\title{
EFFECT OF THE RELATIVE HUMIDITY ON AN INDUSTRIAL PLUME BEHAVIOR
}

\author{
E. AFFAD \\ S. SAADEDDINE* \\ M. ASSOU \\ A. SBAIBI
}

Received: 19/01/06

Accepted: 14/04/06
Laboratoire de Transfert de Chaleur et de Masse Aérothermodynamique - UFR de Mécanique

Faculté des Sciences et Techniques BP 146 Yasmina Mohammedia, 20800, Morocco

*to whom all correspondence should be addressed:

Fax: +21223315353

e-mail: sadedine@uh2m.ac.ma

\begin{abstract}
A lagrangian concept based on the projected area entrainment initially formulated by Winiarski and Frick, and later on developed by Cheung and Lee, is used to predict the effects of some physical properties of the atmosphere which does not appear directly in most empirical formula used to calculate the height of some industrial plume. Special consideration is given to the effects of the atmospheric relative humidity on the plume properties.
\end{abstract}

KEYWORDS: plume trajectory, buoyancy, projected area entrainment, Stack, humidity, atmospheric.

\section{INTRODUCTION}

In order to accurately predict the pollutant concentrations and the plume trajectory in the atmosphere, it is necessary to take into account the effects of interactions between the plume and the surrounding environment. In fact, the atmospheric conditions have a lot of influence on the plume behavior. Earlier models were based on statistical approach. However, this approach presents many shortcomings, in that way they are unable to take directly into account some atmospheric properties such as the moisture of the air. A complete model is the one that solves the entire set of momentum equation completed by energy and species equations. A number of approximate predictive methods for the plume flow in stratified surroundings have been developed in the literature such as Abraham (1965), Schwartz and Tulin (1972), Sneck and Brown (1974), Wright (1984) and Hwang and Chiang (1986).

In this work, we use the lagrangian concept based on the so-called projected area entrainment in its latest formulation (Lee and Cheung 1990) to predict the effect of relative humidity on the plume behavior. Input-required data include source parameters such as the gas exhaust conditions (temperature release, exit velocity, mixing ratios), physical dimensions (diameter and height of stack) and meteorological data. In the present work, only idealized meteorological conditions which neglect the vertical variation of the wind speed, the temperature lapse rate and the relative humidity are considered. The output of the model gives an idea on characteristics parameters of the plume such as its trajectory, its temperature and mixing ratio distribution and its length of visibility. The model validation is accomplished through a comparison of the computed plume maximum height with results obtained using empirical formulas (Hanna, 1972). Also, the calculated plume visibility length is confronted to the ADMS results obtained by Carruthers et al. (2000). The effect of relative humidity is then investigated.

\section{MODELING APPROACH}

Most of the theoretical studies on plume trajectory available in literature (i.e. Weil et al., 1986 and Bursik, 2001) are based on integral models where various plume quantities are assumed constant on the cross-section. In this method, a system of ordinary differential equations is 
used to describe the conservation of mass, momentum and scalar properties through a plume cross-section. A complete overview of the integral plume model concept can be found in Yapa and Zheng (1997). In order to overcome the problems encountered in solving the usual ordinary differential equations, many scientists were inspired by the work of Winiarski and Frick (1976) who have initially formulated the lagrangian concept based on the so-called projected area entrainment. This model uses a series of non-interfering plume elements which increase in mass due to the shear-induced and direct entrainment. This concept was later on developed by Lee and Cheung (1990) and applied to predict the mixing of buoyant jets with three-dimensional trajectories. In this paper, we use this same lagrangian model in its latest formulation to predict the effect of relative humidity on the plume behavior.

The plume element is assumed to be essentially a cylindrical segment whose radius grows as mass is entrained. The initial plume element mass $M_{0}$ is identified as the mass issuing from the stack with initial radius $r_{0}$ and length $h_{0}$ (figure 1 ):

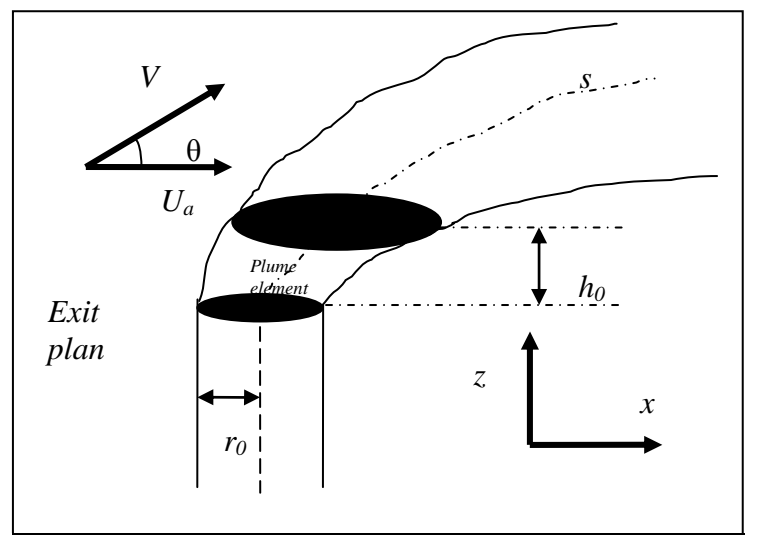

Figure 1. Sketch of initial plume

$\mathrm{M}_{0}=\rho \pi \mathrm{r}_{0}^{2} \mathrm{~h}_{0}$

where $\rho$ is the plume density and $h_{0}$ is given by

$\mathrm{h}_{0}=\mathrm{V}_{0} \Delta \mathrm{t}$

$V_{0}$ is the exit velocity of the plume element.

Two phenomena may contribute to the mass increase of the plume element: the shearinduced entrainment $\left(\Delta \mathrm{M}_{\mathrm{s}}\right)$ and the direct entrainment $\left(\Delta \mathrm{M}_{\mathrm{d}}\right)$

$\Delta \mathrm{M}=\Delta \mathrm{M}_{\mathrm{s}}+\Delta \mathrm{M}_{\mathrm{d}}$

These two contributions are described as follow:

- The contribution of shear entrainment

This contribution is due to the relative velocity of the plume element and the ambient velocity in the direction of the plume axis. In the current model, as done by Lee and Cheung (1990), the shear entrainment contribution $\left(\Delta \mathrm{M}_{\mathrm{s}}\right)$ at each time step $\mathrm{k}$ is computed as:

$\Delta \mathrm{M}_{\mathrm{s}}=2 \pi \alpha \rho_{\mathrm{a}} \mathrm{r}_{\mathrm{k}} \mathrm{h}_{\mathrm{k}}\left|\mathrm{V}_{\mathrm{k}}-\mathrm{U}_{\mathrm{a}} \cos \theta_{\mathrm{k}}\right| \Delta \mathrm{t}$

where $\alpha$ is an entrainment coefficient; $\rho_{a}$ is the ambient air density; $U_{a}$ is the horizontal wind speed; and $r_{k}, h_{k}, V_{k}, \theta_{k}$ are respectively the radius, the height, the magnitude velocity and inclinison angle from the horizontal of the plume element.

- The contribution of direct entrainment

The entrainment due to the cross-flow is modeled using the projected area entrainment hypothesis (Frick, 1984 and Cheung and Lee, 1996). This assumes that the increase in mass $\left(\Delta \mathrm{M}_{\mathrm{d}}\right)$ of the plume element caused by the entrainment due to the cross-flow can be written as follow: 
$\Delta M_{d}=\rho_{a} U_{a}\left[2 r_{k} h_{k} \sin \theta_{k}+\pi r_{k} \Delta r_{k} \cos \theta_{k}+\pi \frac{r_{k}^{2}}{2} \Delta \cos \theta_{k}\right] \Delta t$

where $\Delta$ denotes the variation symbol.

The mass at step $(k+1)$ is computed as:

$\mathrm{M}^{(\mathrm{k}+1)}=\mathrm{M}^{(\mathrm{k})}+\Delta \mathrm{M}$

The model tracks the evolution of average properties of a plume element at each time step by considering the conservation of horizontal and vertical momentum, the conservation of mass accounting for entrainment and the conservation of energy.

The variation of vertical momentum is due to the vertical pressure gradient and the buoyancy force, while the increase of horizontal momentum is only due to the momentum of the entrained mass. Energy variation is related to the variation of temperature. In case where no phase transition occurs, the change in temperature from one time step to the next one may be written as:

$$
\mathrm{T}^{(\mathrm{k}+1)}=\frac{\mathrm{Q}^{(\mathrm{k})}+\Delta \mathrm{Q}_{\mathrm{a}}}{\mathrm{M}^{(\mathrm{k}+1)} \mathrm{C}_{\mathrm{p}}^{(\mathrm{k}+1)}}-\Gamma \Delta \mathrm{z}
$$

where $\mathrm{Q}^{(\mathrm{k})}$ is the plume heat at step $k ; \Delta \mathrm{Q}_{\mathrm{a}}=(\Delta \mathrm{M}) \mathrm{C}_{\mathrm{a}} \mathrm{T}_{\mathrm{a}}$ is the heat content of the mass entrained with ambient temperature $T_{a}$ in the earlier time step; $c_{a}$ and $c_{p}$ are respectively the specific heat capacity of the ambient air and the plume; $\Gamma$ is the atmospheric lapse rate and $z$ is the altitude of plume element.

At each time step, the plume and air densities can be respectively obtained from the equations of state:

$$
\begin{aligned}
& \rho=\frac{P\left(1+\omega_{w}\right)}{R T\left(1+0.622 \omega_{v}\right)} \\
& \rho_{a}=\frac{P\left(1+\omega_{w_{a}}\right)}{R T_{a}\left(1+0.622 \omega_{v a}\right)}
\end{aligned}
$$

where $\omega_{\mathrm{w}}$ and $\omega_{\mathrm{wa}}$ are respectively the liquid water mixing ratio in the plume element and in the ambient air. The pressure $P$ is computed as a hydrostatic pressure, i.e.

$\mathrm{P}=-\rho_{\mathrm{a}} \mathrm{gz}+\mathrm{P}_{0}$

The water vapor mixing ratio $\omega_{v}$ of the plume is expressed as:

$\omega_{v}=0.622 \frac{P_{v}}{P-P_{v}}$

where $P_{v}$ denotes the partial pressure of water vapor.

The water vapor mixing ration in air $\omega_{\mathrm{va}}$ is calculated from the relative humidity RHA as follows:

$\omega_{\mathrm{va}}=\mathrm{RHA} \omega_{\mathrm{vs}}$

The saturated mixing ratio $\omega_{v s}$ is obtained from equation [11] by setting $P_{v}$ to the value of the saturated vapor pressure $P_{\mathrm{vs}}$ that can be calculated using the following formula of Wexler (1976):

$\ln \left(P_{v s}\right)=\sum_{i=0}^{6} a_{i} T^{i-2}+a_{7} \ln T$

where the value of the coefficients $a_{i}$ are given in the above reference.

The condensation is encountered when the mixing ratio of the mixed parcel is larger than the saturated mixing ratio for the corresponding temperature. In this situation, the temperature change caused by the phase transition can be calculated from the following expression of specific enthalpy:

$\mathrm{h}=\left(\begin{array}{llllll}\mathrm{c}_{\mathrm{d}}+\omega_{\mathrm{v}} & \mathrm{c}_{\mathrm{v}}+\omega_{\mathrm{w}} & \mathrm{c}_{\mathrm{w}}\end{array}\right) \quad \mathrm{T}+\left(\begin{array}{llll}\omega_{\mathrm{v}} & \mathrm{c}_{\mathrm{w}}-\omega_{\mathrm{v}} & \mathrm{c}_{\mathrm{v}}\end{array}\right) \mathrm{T}_{0}+\omega_{\mathrm{v}} \quad \mathrm{L}_{\mathrm{e}}$ 
In this formula $c_{d}, c_{v}, c_{w}$ are the specific heat of the dry air, water vapor and liquid water; $L_{e}$ is the latent heat of vaporization of water at $0^{\circ} \mathrm{C}$ and $T_{0}$ is the freezing point of water.

The iterative resolution of the system of the above equations, allows us to have the plume position (horizontal distance $x$ and vertical distance $z$ ); its velocity; its temperature; its mass and its composition (mixing ratios). The dilution criterion, used to end the iterative procedure, is considered when the plume density and speed are virtually indistinguishable from the ambient values.

\section{Numerical Results and discussions}

Validation of the model

In order to validate the model used, we compare our result against empirical and observed values. This comparison is done for three different source and atmospheric conditions as shown in table 1.

Table 1. Ambient and source conditions

\begin{tabular}{|c|c|c|}
\hline Case 1 & Case 2 & Case 3 \\
\hline $\begin{array}{l}\text { Source conditions } \\
\text { plume temperature: } 361.45 \mathrm{~K} \\
\text { flow rate: } 29.7 \mathrm{~m}^{3} \mathrm{~s}^{-1} \\
\text { water vapour mixing ratio: } 0.023 \\
\text { molar fraction } \mathrm{H}_{2} \mathrm{O}: 0.01926 \\
\text { source diameter: } 5.4 \mathrm{~m} \\
\text { source height: } 108 \mathrm{~m} \\
\text { Atmospheric conditions } \\
\text { wind speed: } 6 \mathrm{~m} \mathrm{~s}^{-1} \\
\text { relative humidity: } 20 \% \text { to } 90 \%\end{array}$ & $\begin{array}{l}\text { Source conditions } \\
\text { plume temperature: } 306.15 \mathrm{~K} \\
\text { flow rate: } 3 \mathrm{~m}^{3} \mathrm{~s}^{-1} \\
\text { water vapour mixing ratio: } 0.032 \\
\text { molar fraction } \mathrm{H}_{2} \mathrm{O}: 0.049 \\
\text { source diameter: } 0.4 \mathrm{~m} \\
\text { source height: } 26.4 \mathrm{~m} \\
\text { Atmospheric conditions } \\
\text { wind speed: } 2 \mathrm{~m} \mathrm{~s}^{-1} \\
\text { relative humidity: } 85.5 \%\end{array}$ & $\begin{array}{l}\text { Source conditions } \\
\text { plume temperature: } 308.15 \mathrm{~K} \\
\text { flow rate: } 3.2 \mathrm{~m}^{3} \mathrm{~s}^{-1} \\
\text { water vapour mixing ratio: } 0.036 \\
\text { molar fraction } \mathrm{H}_{2} \mathrm{O}: 0.0557 \\
\text { source diameter: } 0.4 \mathrm{~m} \\
\text { source height: } 26.4 \mathrm{~m} \\
\text { Atmospheric conditions } \\
\text { wind speed: } 2 \mathrm{~m} \mathrm{~s}^{-1} \\
\text { relative humidity: } 81.9 \%\end{array}$ \\
\hline
\end{tabular}

The calculated maximum plume height $\Delta \mathrm{H}$ is compared to the results obtained by the empirical formula suggested by Hanna (1972) for the source and atmospheric conditions labeled as case 1 in table 1 and for different values of relative humidity ranging from 20\% to $90 \%$. Results of this comparison are presented in table 2 .

Table 2. Maximum plume height

\begin{tabular}{lcc}
\hline $\begin{array}{l}\text { Relative Humidity } \\
\text { (percent) }\end{array}$ & $\begin{array}{c}(\Delta \mathrm{H})_{\text {model }} \\
(\mathrm{m})\end{array}$ & $\begin{array}{c}(\Delta \mathrm{H})_{\text {empirical }} \\
(\mathrm{m})\end{array}$ \\
\hline 20 & 39.70 & 46.40 \\
30 & 41.23 & 46.22 \\
40 & 42.78 & 46.03 \\
50 & 44.27 & 45.84 \\
70 & 47.63 & 45.46 \\
90 & 49.27 & 45.13 \\
\hline
\end{tabular}

The values obtained using the present model, are rather comparable with those obtained empirically. Nevertheless, our calculated maximum plume elevation is predicted to be between 39.7 and $49.27 \mathrm{~m}$ when the relative humidity varies from 20 to $90 \%$, while the results obtained with Hanna formula are slightly sensitive to relative humidity variation. The difference between these two results could be related to the fact that the model used here takes into account the evolution of the physical properties of the plume and not only the initial conditions as it is the case of the empirical formula.

The second set of comparison relies on plume visibility length. In fact, for the supersaturated plume, some of the water vapor condenses into small liquid droplets. Light scattering from the liquid droplets allows the plume to be visible. The length of visibility is a complex function of the source operating and meteorological conditions. A comparison of this plume length visibility with some observed data is also made. In this work, we have used the initial vapor content of the plume and the humidity of the ambient air to predict whether the plume will be 
visible at each downstream distance or not. The results of this comparison are shown in table 3.

Table 3. Plume visibility length

\begin{tabular}{lccc}
\hline & Observed visible plume length & Used model & ADMS model \\
$(\mathrm{m})$ & $(\mathrm{m})$ & 0.4 \\
\hline Case 2 & 5 & 7.01 & 0.4 \\
Case 3 & 2 & 3.86 & \\
\hline
\end{tabular}

The calculations are performed by using two different source and atmospheric conditions that were previously used by Carruthers et al. (2000) in their ADMS model calculation. These two conditions are labeled as case 2 and 3 in table 1 . According to table 3 , both the observed and our model values show that the condition suitable for a visible plume will occur at high relative humidity. The results obtained with the present model show a good agreement with the observed visible plume length, while the ADMS model results show no variation of the visible plume length with the relative humidity. The discrepancy between ADMS results and the observed values was also noted by Carruthers et al. (2000) who found that for shorter stack with lower water mixing ratio (similar case to the one used in this study) a near zero visible plume lengths are predicted with ADMS model. This seems to be a shortcoming characteristic of ADMS model.

\section{The effect of relative humidity}

In order to investigate the effect of the relative humidity on the plume properties, we show on figure 2 the trajectories of the plume for the same exit and meteorological conditions as taken in case 1 for three different relative humidity values (i.e. $50 \%, 70 \%$ and $90 \%$ ).

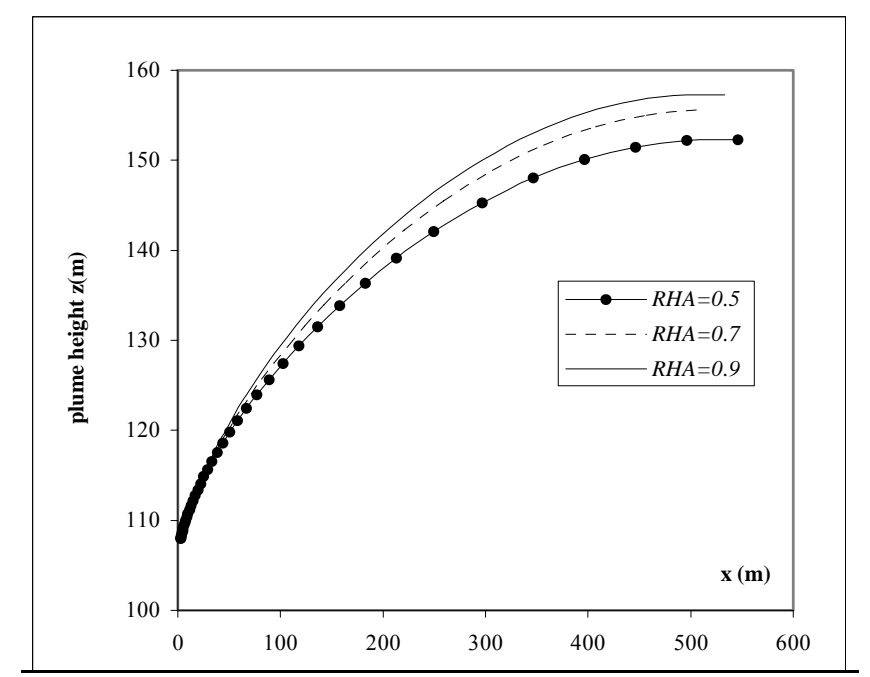

Figure 2. Effect of the humidity on the plume trajectory

One can distinguish on theses curves two different zones in function of the horizontal distance:

- a zone where all the curves are close to each other for all conditions of relative humidity. The plume is almost insensitive to atmospheric moisture. In other words, the effect of increased relative humidity was found to be less significant near the exit chimney.

- a second zone where the curves are separate; and the increase in the relative humidity has a greater effect on the plume rise than in the first region.

To explain this observation, we represent on figure 3 , the quantity $\frac{d f_{b}}{d s}$ which represents the variation of buoyancy force $\left(\mathrm{N} \mathrm{m}^{-1}\right)$ versus the centerline coordinate. One can note on this figure that each of theses curves represents two zones: a zone where this variation is positive thus generating an acceleration of the plume, and another zone where the plume undergoes a deceleration (negative variation). The same figure shows that the more the moisture 
increases the more the plume is subjected to a relatively important buoyancy force. Being subjected to this force, the plume would have an acceleration (or deceleration) more important when the atmospheric relative humidity increases. A greater value of relative humidity will induce a greater value of the water vapor mixing ratio. A look of expression (8) show that an increase of $\omega_{v}$ result in a decrease of $\rho$ which, in turn, increases the buoyancy driving force. On another hand, for the same mass a decrease in $\rho$ will have to be accompanied by an increase of the volume and therefore an increase of its radius.

Figure 4 shows the variation of the plume radius versus time for the three values of relative humidity. This atmospheric parameter greatly influences the expansion of the plume. In fact, for a given elapsed time the plume would have a larger radius for larger atmospheric moisture. Due to mass diffusion, the quantity of water vapor contained in the plume element increases with atmospheric relative humidity. This is well represented in figure 5 where the mass of vapor in the plume element is represented versus the centerline distance. The increase of water vapor in the plume element prevents from a sharp decrease of plume element temperature. This can be easily explained by considering the great difference in the specific heat value relative to air and water vapor.

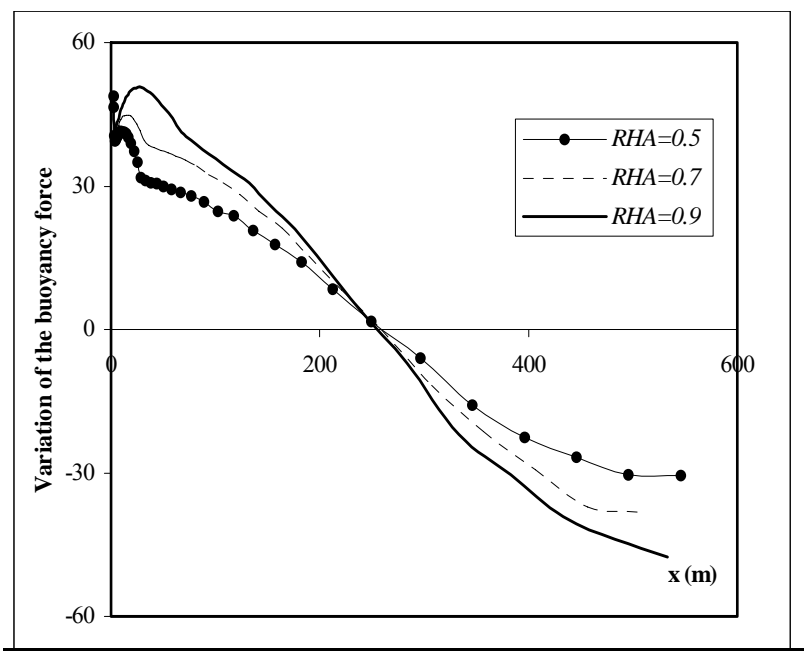

Figure 3. Variation of the force versus the downwind distance

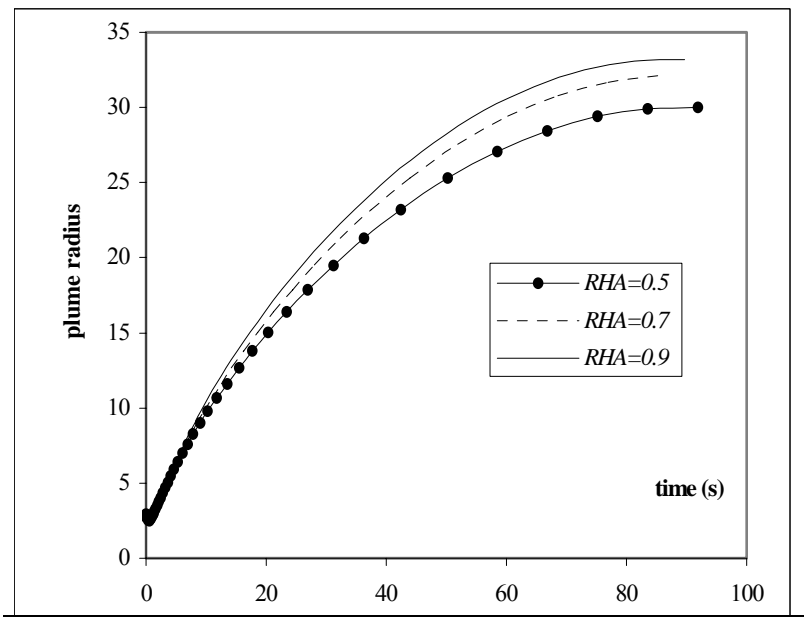

Figure 4. Effect of the relative humidity on the plume radius expansion elapsed time 


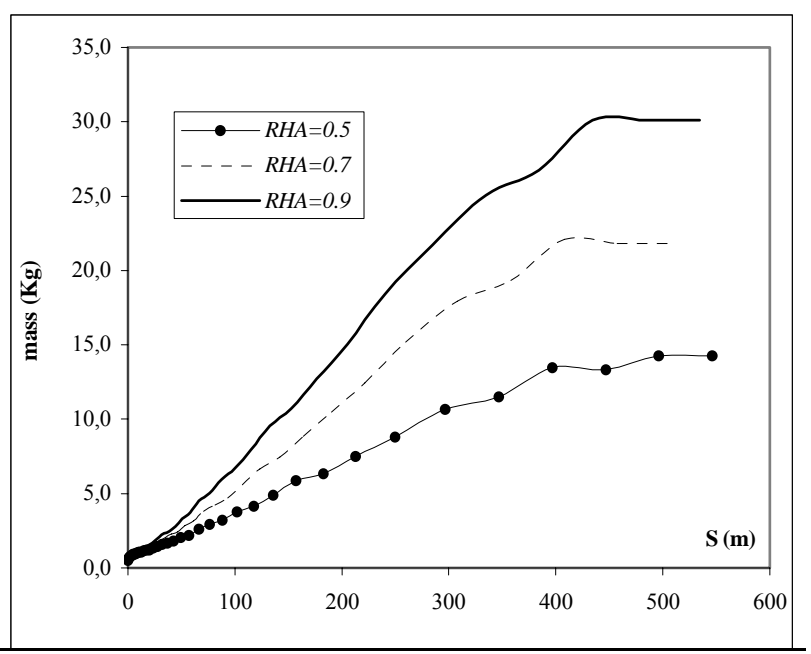

Figure 5. Evolution of the plume element water vapor mass versus its centerline distance

Figure 6 shows the variation of the element temperature versus the centerline distance for different values of the relative humidity. As anticipated above, the decrease of the plume element temperature is faster in the case of lower relative humidity.

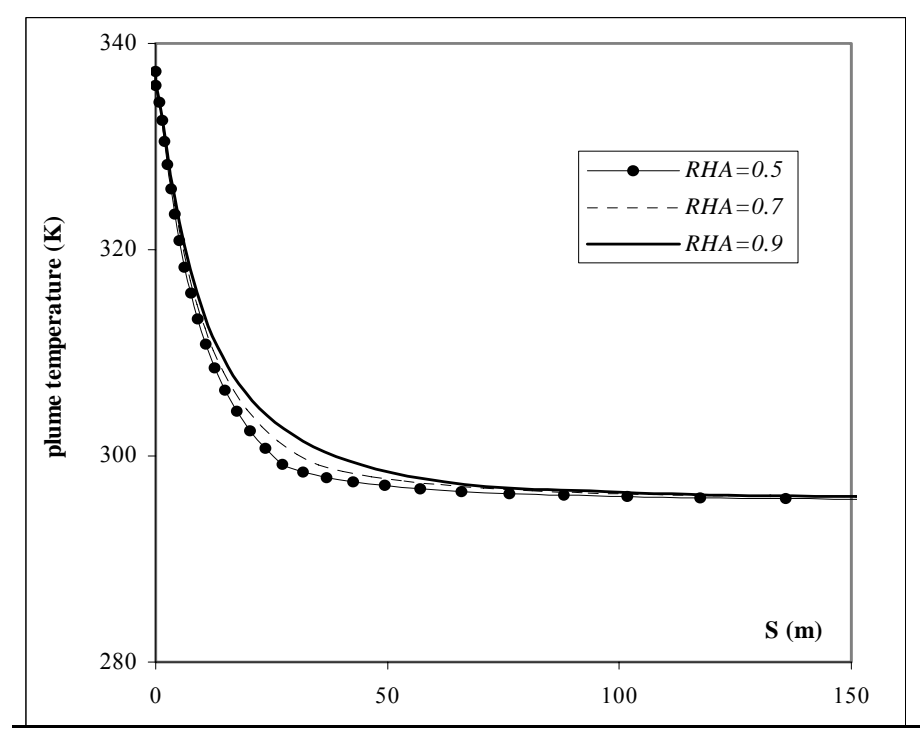

Figure 6. Plume temperature variation versus the centerline distance for different RHA

\section{CONCLUSION}

A study of the evolution of the plume rise and its characteristics was conducted using a lagrangian concept based on the projected area entrainment. The terminal plume rise criterion is taken when the plume is sufficiently diluted in the ambient surroundings. Special emphasis was put on the effect of relative humidity on a number of the plume characteristics including the plume radius, its temperature and also the evolution of its vapor mass during the rising phase. The results obtained from the model present a good agreement with some existing empirical and observed data. Although the effect of the relative humidity on plume composition (vapour mass) is notable, its effect on the plume rise, plume radius and plume temperature remain relatively slight.

The next step will be to include these finding as starting point to predict the ground concentration of the pollutant dispersion from an industrial plume and to assess the influence of the humidity on the concentration levels. 


\section{ACKNOWLEDGMENT:}

The present work was partly supported from the Moroccan Ministry of higher education, scientific research division through PROTARS grant $\mathrm{P} 2 \mathrm{~T} 2 / 08$.

\section{NOMENCLATURE}

$M_{0} \quad$ initial plume mass

$\rho \quad$ plume density

$r_{k} \quad$ radius of plume element at time step $k$

$h_{k} \quad$ height of plume element at time step $k$

$V_{k} \quad$ magnitude of the plume velocity at time step $\mathrm{k}$

t time

$\Delta \mathrm{M}_{\mathrm{S}}$ shear-induced mass

$\Delta \mathrm{M}_{\mathrm{d}}$ direct-entrained mass

$\Delta \mathrm{M}$ mass increase of the plume element

$\alpha \quad$ entrainment coefficient

$\rho_{\mathrm{a}} \quad$ ambient air density

$\mathrm{U}_{\mathrm{a}} \quad$ horizontal wind speed

$\theta_{\mathrm{k}}$ plume inclinison angle from the horizontal

$M^{(k)}$ mass of plume element at step $k$

$\mathrm{T}^{(\mathrm{k})} \quad$ plume temperature at step $k$

$\mathrm{Q}^{(\mathrm{k})}$ plume heat at step $k$

$\Delta \mathrm{Q}_{a}$ heat content of the mass entrained with ambient temperature $T_{a}$ in the last time step

$\Gamma \quad$ ambient lapse rate

$\mathrm{c}_{\mathrm{p}}^{(\mathrm{k})} \quad$ specific heat of the plume at step $k$

$\mathrm{c}_{\mathrm{a}} \quad$ specific heat capacity of ambient air

z altitude of the plume element

$\mathrm{P}$ total pressure

$\omega_{\mathrm{w}} \quad$ liquid water mixing ratio of plume

$\omega_{\mathrm{v}} \quad$ mixing ratio of water vapor

$\omega_{\text {wa }}$ liquid water mixing ratio of ambient air

$\omega_{\mathrm{va}}$ water vapor mixing ratio of ambient air

$P_{v} \quad$ partial pressure of water vapor

RHA relative humidity of air

$\omega_{\mathrm{vs}}$ saturated mixing ratio

$\mathrm{P}_{\mathrm{vs}} \quad$ saturated vapor pressure

$h \quad$ specific enthalpy of plume

$c_{d}$ specific heat of dry air at constant pressure

$c_{v} \quad$ specific heat of water vapor at constant pressure

$\mathrm{c}_{\mathrm{w}} \quad$ specific heat of liquid water at constant pressure

$\mathrm{T}_{0} \quad$ freezing point of water

$\mathrm{L}_{e} \quad$ latent heat of vaporization of water at $0^{\circ} \mathrm{C}$

$\Delta \quad$ variation symbol

$\Delta \mathrm{H} \quad$ maximum plume height

$F_{b}$ buoyancy force

$\mathrm{s}$ centerline distance

$\mathrm{x}$ downwind distance

$\mathrm{T}_{\mathrm{a}}$ ambient temperature

\section{REFERENCES}

1. Abraham G. (1965) Entrainment principle and its restriction to solve jet problems, Journal of Hydraulic Research, 31, 1-23.

2. Bursik M. (2001) Effect of Wind on the rise height of volcanic plumes, Geophysical Research Letters, 28, 3621-3624.

3. Carruthers D.J., Dyster S.J. and Ellis K.S. (2000) Plume visibility, Technical Specification Paper, P26/01C/00.

4. Cheung V. and Lee J.H.W. (1996) Discussion of Improved prediction of bending plumes, Journal of Hydraulic Research, 34, 260-262.

5. Frick W.E. (1984) Non-empirical closure of the plume equations, Atmospheric Environmental, 18, 653-662.

6. Hanna S.R. (1972) Rise and condensation of large cooling tower plumes, Journal of applied meteorology, 11, 793-799.

7. Hwang R.R. and Chiang T.P. (1986) Buoyant jets in a cross-flow of stably stratified fluid, Atmospheric Environment, 20, 1887-1890.

8. Lee J.H.W. and Cheung V. (1990) Generalized Lagrangian model for buoyant jets in current, Journal of Environmental Engineering, ASCE, 116, 1085-1105.

9. Schwartz J. and Tulin M.P. (1972) On the mean path of buoyant bent-over chimney plumes, Atmospheric Environment, 6, 19-36.

10. Sneck H.J. and Brown D.H. (1974) Plume rise from large thermal sources such as cooling tower, ASME Journal of the heat transfer, 96, 232-238. 
11. Weil J.C., Corio L.A. and Brower R.P. (1986) Dispersion of buoyant plumes in the convective boundary layer, Proceeding of the $5^{\text {th }}$ Joint Conference On Applications of Air Pollution Meteorology Society, Boston, MA. 335-338.

12. Wexler A. (1976) Vapor pressure formulation for water in range 0 to $100{ }^{\circ} \mathrm{C} . \mathrm{A}$ Revision, $\mathrm{J}$. Res. Nat. Bur. Stand., 80A. 775-785.

13. Winiarski L.D. and Frick W.E. (1976) Cooling tower Plume model, CERL, USEPA, Corvallis, OR. EPA-600/3-76-100

14. Wright S. (1984) Buoyant jets in density stratified cross-flow, Journal of Hydraulic Division, ASCE, 10, 643-656.

15. Yapa P.D. and Zheng L. (1997) Modeling oil and gas releases from deep water, A Review, Spill Science \& Technology Bulletin, 4, 189-198. 